\title{
One of Steel Structure Reinforced Ship lift Platform Quality Inspection and Load Test
}

\author{
Liqiang Jin, Huainian Xing, Zengli Liu, Da Li, Kai Sun, Shuhui Li, Xiaopeng \\ Zhang
}

Department of engineering mechanics, Dalian university of technology; Dalian; 116024

introduction

KEYWORD: the ship lift platform of steel structure; loading test; load-bearing capacity; stress test ABSTRACT: With the development of marine transport, ship timely maintenance and repair of performance as one of the main factors affecting the efficiency of transport. Ship lift platform of steel structure provides appropriate maintenance and docking capability for marine areas, while steel platform has many advantages: for example, moderate stability, good earthquake resistance capacity and reasonable load-bearing capacity. The paper presents a project example, through the detection of a ship lift platform structure reinforcement engineering overall quality, and using a simplified model combined with the calculation of load testing method, it can determine whether the ship meets the requirement of platform.

Marine transport is the main mode of transportation in international trade, countries all over the world are making great efforts to expand port scale, and actively build and develop their own fleet, therefore ships can continue normal transport links developed advanced maintenance. This embodies the important place of ship lift platform. Because of light weight, good toughness, convenient construction and good rigidity and other characteristics, the steel structure of ship lift platform are widely and frequently used. Since the platform structure often soaked by seawater causing serious corrosion, which greatly affect the overall stability of the steel structure of ship lift platform. So as to avoid sudden failures and accidents of the ship lift platform, we must draw attention to the steel structure of ship lift platform security and checks on a regular basis.

This paper describes a detection of a ship lifting platform structure reinforcement engineering overall quality. By using the simplified model method, calculating and analyzing the structure in the case of theoretical load, through ship field loading tests, determine whether the structure in line with bearing capacity standards. then it can providing a reference for other similar ship lifting platform structure reinforcement engineering.

\section{SHIPLIFTING PLATFORM DESIGN}

\section{Ship lift platform plane size determine}

After selecting the ship platform design type, the width of the platform determined as follow (Figure 1):

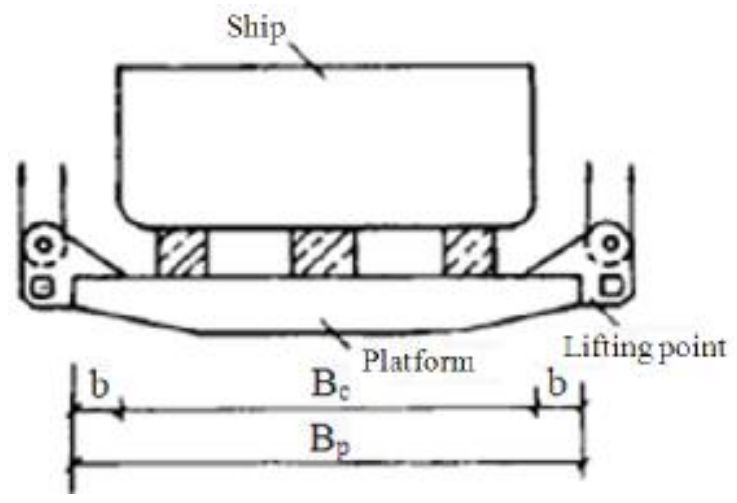

Figure 1. 
$\mathrm{B}_{\mathrm{p}}=\mathrm{B}_{\mathrm{c}}+2 \mathrm{~b}$

where $\mathrm{B}_{\mathrm{p}}=$ the width of the platform; $\mathrm{B}_{\mathrm{c}}=$ the width of the ship; $\mathrm{b}=$ the rich width.

The length of the platform determined as follow (Figure2):

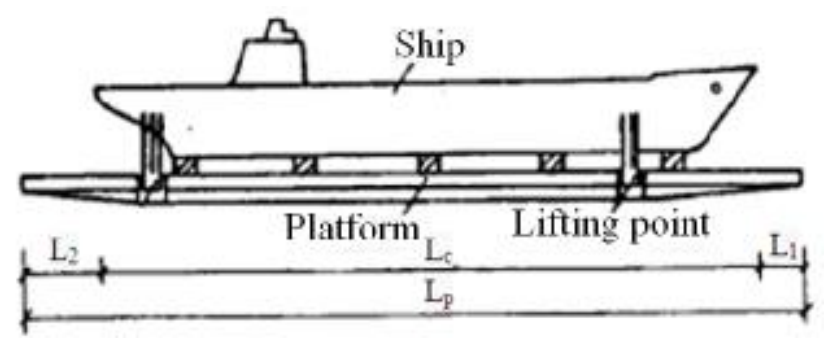

Figure 2.

$\mathrm{L}_{\mathrm{p}}=\mathrm{L}_{\mathrm{c}}+\mathrm{L}_{1}+\mathrm{L}_{2}$

where $L_{p}=$ the length of the platform; $L_{c}=$ the length of the ship; $L_{1}=$ the bow rich length; $L_{2}=$ the poop rich length.

The value of the bow rich length is usually $1.5 \mathrm{~m} \sim 2 \mathrm{~m}$, the value of the poop rich length is usually $2.0 \sim 4.0 \mathrm{~m}$, In order to repair propeller blades and tail shaft on the platform comfortably. If it is not on the platform, L2 can equal to L1. Usually selecting the length of the platform is generally not as strict as width. But for split articulated platform, the size of the middle active platform must be same, so as to give a convenience to platform extension in the future.

\section{Platform structure selection}

The platform structure selection mainly depends on using environment and load. If using environment is fresh water, we adopt I-girder grid system cross section to save steel, saving than using box section steel about $10 \%$; If using environment is sea water, especially loads by buttress, the main bearing beam cross section selects closed box section as well, we can slow down the corrosion of the steel structure by the sea, and increase the torsional stiffness of the beam. In order to save investment, we usually try to reduce ship lift platform harbor basin building height, so the ship lift platform can be using in tidal level waves splash zone. In order to ensure the steel structure can be normal used and prolong service life, we should consider corrosive allowance during designing, structure design life of 20 years. Selection of platform structure is divided into three types: overall platform, block articulated platform and segmental type platform.

\section{Platform design loads determination}

Platform design loads are usually two conditions: one is moving ship car load. It relates with the number of moving ship car, arrangement spacing, and the car's wheelbase. Using structural mechanics influence line method, we determine the most unfavorable loading position; another is ship moved platform buttress load, it determines by load division method, unbalanced coefficient method, rigid support continuous beam method, elastic supported continuous beam method and the ship along the longitudinal, transverse load division method.

\section{Project Overview}

Dalian Ocean Shipping voyage repair factory, a 400 tons simple ship lift facilities are made of hydraulic structures, ship lift platform, hoisting devices, mechanical equipment, and electrical equipment. Among them, ship lift platform is beam plate welded structure, using three linkage platform, the front and the back are active platforms, 16 meters length, 14 meters width, the middle is driven platform, 12 meters long, and 14 meters wide. The whole platform is made of four main beams, setting up eight lifting points. The platform is established in 1992, completed in January 
1993, the original design of bearing capacity is 600 tons. After field survey, it is very frequent for the facilities to be used for repairing ship about 20. Each ship is 500-600 tons weight, the heaviest is 700 tons weight. There are a lot severe corrosions due to bad environment, tidal fluctuation, soaked in the sea water. We restrict the maximum ship loads no more than 270 tons after evaluating ship lift platform structure detection and bearing capacity. In order to ensure security and production use, we give a suggestion that the ship lift platform need be reinforced and anticorrosive, increasing the maximum ship weight loads by 400 tons. So we need detect the reinforcement engineering quality, conduct performance static load test, to verify which meet the existing hoisting capacity requirements of reinforced platform.
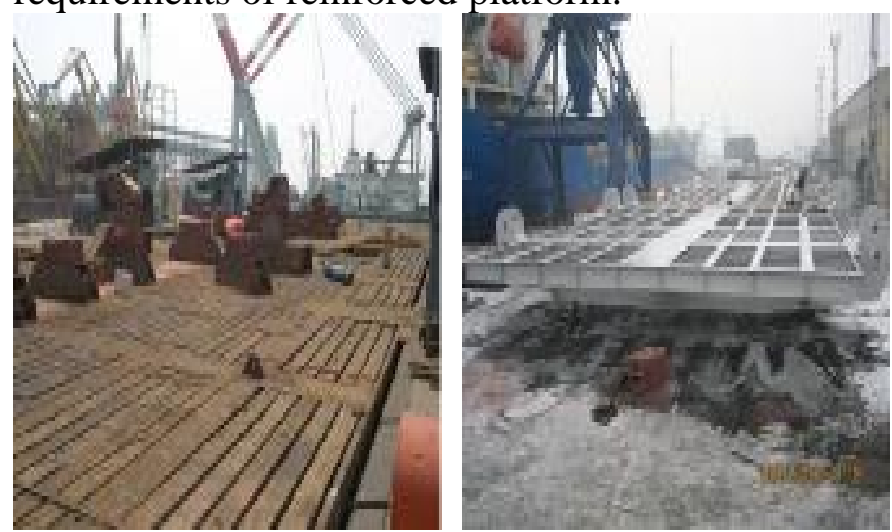

Figure 3. The ship lift platform before and after reinforcement

\section{reinforced structure quality test}

In this paper, the quality of structural reinforcement is tested from the strength of steel, welding quality, section size of reinforcement steel, the thickness of structure anticorrosion coating, and so on. After detection, there are no defects which affect structure capability. We judge that the quality of ship lifting platform structural reinforcement is very well. These provide the basis for structural theory analysis and loading test. Test results are shown in table 1.

Table 1. Quality inspection results of reinforced structure.

\begin{tabular}{|c|c|c|c|}
\hline Project & Standard & $\begin{array}{l}\text { Detect } \\
\text { ion result }\end{array}$ & $\begin{array}{l}\text { Deter } \\
\text { mine }\end{array}$ \\
\hline Steel strength(MPa) & $470-630$ & $510-540$ & Qualified \\
\hline Welding quality & Second level & $\begin{array}{l}\text { Second } \\
\text { level }\end{array}$ & Qualified \\
\hline $\begin{array}{l}\text { Section size of } \\
\text { reinforcement } \\
\text { steel }(\mathrm{mm})\end{array}$ & $16_{0.450 .85}^{-+}$ & $\begin{array}{l}15.74- \\
16.03\end{array}$ & Qualified \\
\hline $\begin{array}{l}\text { Anticorrosive } \\
\text { coating thickness } \\
(\mu \mathrm{m})\end{array}$ & $\geq 425$ & $451-535$ & Qualified \\
\hline
\end{tabular}

\section{LOAD TEST PROGRAM}

According to the provisions for static load test of steel structure performance in GB/T503442004 "Technical standard for inspection of building structures" appendix $\mathrm{H}$ and items in the contract, this test belongs to structural performance inspection, testing scheme is as follows:

\section{Maximum test load}

According to GB/T50344-2004 appendix H.2.3 steel structure performance test load, the following load shall be taken:

Actual weight * 1.0;

Other dead load $* 1.15$; 
Variable load $* 1.25$

Actual weight is abiding, no other dead load, variable load is ship weight load, so the maximum load is $400 * 1.25=500$ (ton).

\section{Load classification}

According to GB/T50344-2004 appendix H.1.4, the test load should be rated load, each load need no more than $20 \%$ of the maximum load, this maximum load is 500 tons, rated loads are divided into 5 levels: 100 tons, 200 tons, 300 tons, 400 tons, and 500 tons. Loading arrangement schematic diagram shown in Figure 4. Load picture the scene shown in Figure 5.

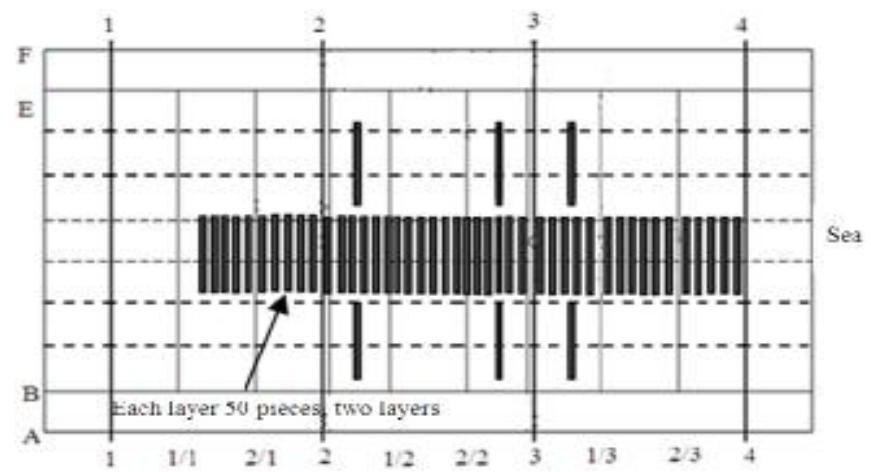

Figure4. Loading arrangement schematic diagram

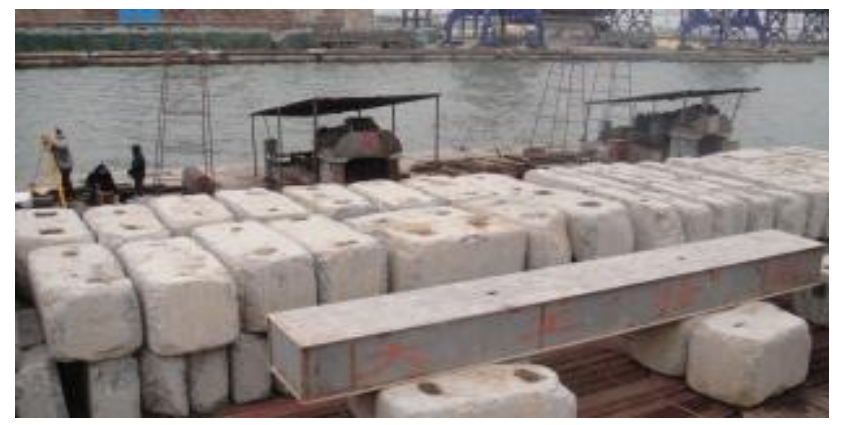

Figure5. Load picture the scene

\section{Deformation (Maximum deflection) test}

According to GB/T50344-2004 appendix H.1.5, we should record load deformation curve in loading process. In H.1.6, when it reaches maximum load for performance test, we should hold at least 1 hour, taking a test load and deformation values at every 15 minutes. Until there are no deformations changed in 15 minutes. Then we can load shedding, take a test load and deformation values at every level load. It is stipulated that residual deformation must be no more than $20 \%$ of the recording maximum deformation.

According to JTJ283-1999 "Code for design of steel structure in Port Engineering" clause 6.3.2, The maximum deflection of the bending member should not exceed L/500, L- calculated span.

We all set fixed point on the primary member. We survey the main test beam at all levels under the load deformation with total station. Arrangement of measuring points is shown in Figure 6. 


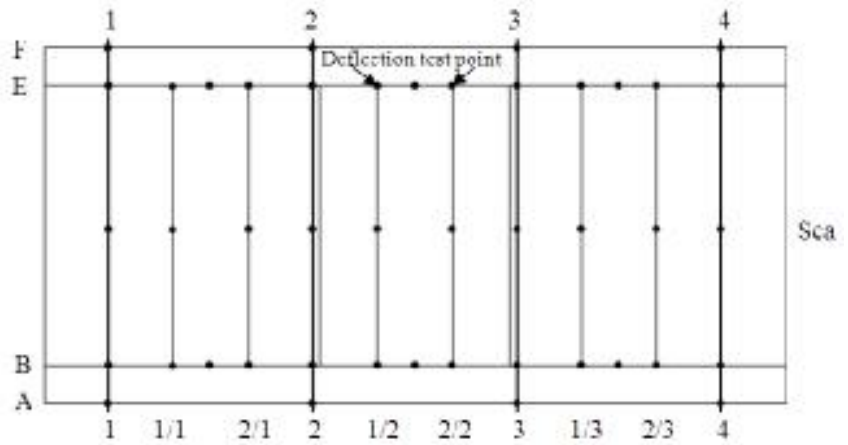

Figure6. Arrangement of measuring points

\section{Stress test}

According to JTJ283-1999 clause 6.3.2, The design value of tensile strength and compressive strength of Q345 steel is $310 \mathrm{MPa}$, and the design value of shear strength is $180 \mathrm{MPa}$.

We use electrometric methods to test the stress, set stress test point on the main load-bearing beam, affix a unidirectional resistance strain sheet on each middle beam bottom flange along the beam length, affix right-angle strain rosettes on the middle of the beam end web. We need both affix strain rosette on the both ends of $2 \#, 3 \#$ main beam. Because $3 \#$ main beam bears the largest load, we affix a strain gage on the top flange material, affix a strain gage on the bottom flange material, affix right-angle strain rosettes on 3-E lifting eye.DH3816 static strain test system is used to test. Measuring point diagram is shown in figure 7.

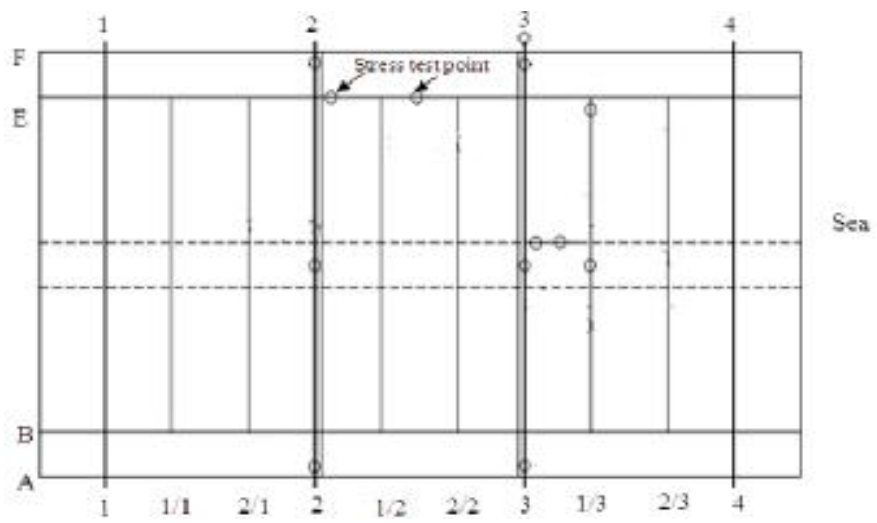

Figure7. Measuring point diagram

The stress value of the test is unrecorded load, and the stress caused by the dead weight should be compared with the design value.

\section{Test procedure}

According to the test program, we affix resistance strain gauges to the stress test point, arranged test leads.

When variable load is zero, measuring each strain and initial deformation.

According to clause 4.2, we gradually apply load, each stage load is uniform distribution within the overall range.

Measuring each strain and deformation under each stage load. Main stress point welding should not appear crack, calculating the deflection value and stress values of main test point under each load, they are should not more than the design value and standard requirements, what is more, the increment of strain and deflection is linear relationship. If not, we should stop test immediately, and then decide how to conduct follow-up test after research and judgment.

Under normal conditions, meet the request of clause 4.1, we can terminate the test. 


\section{LOAD TEST RESULTS}

\section{Predigestion model calculation}

The stress of the beam is simplified to figure 8 .

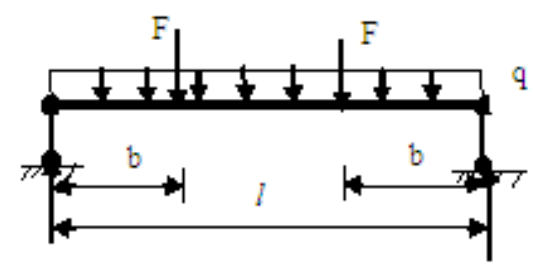

Figure 8. Simplified model of the beam

Where $l=$ the length of beam; $F=$ the approximate value of gravity load sharing of the beam; $b=$ the distance from the focus to the fulcrum; $q=$ uniform load.

Approximate calculation formula of deflection:

$\omega_{\max }=\omega_{l / 2}=\frac{-5 q l^{4}}{384 E I}+\frac{-F b}{48 E I}\left(3 l^{2}-4 b^{2}\right)$

Calculation formula of normal stress:

$\sigma=\frac{M y}{I}$

Where $M=$ the moment on the cross section; $y=$ coordinate of the point; $M \& y$ are algebraic quantity, $I=$ the moment of inertia of the neutral axis in the face of the cross section, it is related to the shape and size of the cross section.

\section{Deformation (maximum deflection) test results}

According to the practical application, the test load concentrated near the 2 \#, 3 \# main beam, this article also analyzes these data. The deformation increment of test point is linear relationship, unloaded residual deformation need less than $20 \%$ of the maximum deformation value. Each beam maximum deflection value is less than 1/500 span.

Table 2. Deformation measurement results $(\mathrm{mm})$

\begin{tabular}{lllllll}
\hline Position & $\begin{array}{l}2 \# \\
\text { main } \\
\text { beam }\end{array}$ & $\begin{array}{l}3 \# \\
\text { main } \\
\text { beam }\end{array}$ & $\begin{array}{l}1 / 2 \\
\text { beam }\end{array}$ & $\begin{array}{l}2 / 2 \\
\text { beam }\end{array}$ & $\begin{array}{l}1 / 3 \\
\text { beam }\end{array}$ & B-2-3 \\
\hline $\begin{array}{l}\text { Allowable } \\
\text { deflection }\end{array}$ & 28.0 & 28.0 & 21.6 & 21.6 & 21.6 & 24.0 \\
$\begin{array}{l}\text { L/500 } \\
\text { Max } \\
\text { deflection }\end{array}$ & 9.5 & 10.5 & 5.0 & 6.5 & 7.5 & 6.5 \\
$\begin{array}{l}\text { Max } \\
\text { deflection } \times 20\end{array}$ & 1.9 & 2.1 & 1.0 & 1.3 & 1.5 & 1.3 \\
$\begin{array}{l}\% \\
\text { Residual } \\
\text { deformation }\end{array}$ & 0.5 & 0.5 & 0 & 0 & 0.5 & 0 \\
$\begin{array}{l}\text { Maximum } \\
\text { deflection } \\
\text { theory }\end{array}$ & 11.3 & 12.4 & 5.0 & 5.8 & 7.0 & 6.0 \\
$\begin{array}{l}\text { Maximum } \\
\text { deflection } \\
\text { error }(\%)\end{array}$ & -15.9 & -15.3 & 0 & 12.1 & 7.1 & 8.3 \\
\hline
\end{tabular}

\section{Stress (maximum deflection) test results}

Theoretical calculation and actual load arrangement show that 3 \# main beam stress is the largest, so stress analysis in 3 \# main beam as an example, the data are shown in table 3 . The stress increment of test point is linear relationship, unloaded residual stress is zero. It specifies material online within the elastic range. Maximum stress (maximum load stress + gravity stress) does not 
exceed the material strength design value. 3 \# main beam across the middle and lower flange raw material and reinforced plate test results are congenial. That shows the quality of reinforcement weld is very well.

Table 3. Stress measurement results (MPa)

\begin{tabular}{cccccc}
\hline & \multicolumn{5}{c}{ 3\# main beam } \\
\cline { 2 - 6 } Load (t) & $\begin{array}{c}\text { End } \\
(\mathrm{A})\end{array}$ & $\begin{array}{c}\text { Mid } \\
\text { (under } \\
\text { original) }\end{array}$ & $\begin{array}{c}\text { Mid } \\
\text { (under } \\
\text { reinforce) }\end{array}$ & $\begin{array}{c}\text { Mid } \\
\text { (above } \\
\text { original) }\end{array}$ & $\begin{array}{c}\text { End } \\
(\mathrm{F})\end{array}$ \\
\cline { 2 - 6 } & $\begin{array}{c}\text { Shear } \\
\text { stress }\end{array}$ & $\begin{array}{c}\text { Normal } \\
\text { stress }\end{array}$ & $\begin{array}{c}\text { Normal } \\
\text { stress }\end{array}$ & $\begin{array}{c}\text { Normal } \\
\text { stress }\end{array}$ & $\begin{array}{c}\text { Shear } \\
\text { stress }\end{array}$ \\
\hline 0 & 0 & 0 & 0 & 0 & 0 \\
100 & 12.2 & 27.5 & 27.6 & -27.2 & 12.0 \\
200 & 23.8 & 55.3 & 55.5 & -54.9 & 23.7 \\
300 & 35.5 & 83.0 & 83.4 & -82.4 & 35.5 \\
400 & 47.3 & 110.7 & 111.2 & -110.0 & 47.4 \\
500 & 48.9 & 138.5 & 139.1 & -137.8 & 49.2 \\
0 & 0.3 & 0.7 & 0.6 & -0.8 & 0.2 \\
Self stress & 3.3 & 10.5 & 10.5 & -10.5 & 3.3 \\
Total stress & 62.2 & 149.0 & 149.6 & -148.3 & 62.5 \\
Theoretical & 45.6 & 171.5 & 172.2 & -171.5 & 45.6 \\
Error (\%) & 0.7 & 19.2 & 19.2 & 19.6 & 7.9 \\
\hline
\end{tabular}

\section{The error analysis}

The data in table 2 and table 3 can be seen that the deformation test maximum error is $15.9 \%$, the stress test maximum error is $19.6 \%$. The main source of error are: (1)the error dues to the difference between loading and simplified model (2)the error dues to difference between the actual cross section size (such as rested) and calculation size, (3)the error dues to the instrument equipment, etc. The analysis results show that the theoretical calculation is consistent with the actual measurement, which verifies the correctness of the theoretical analysis.

\section{Conclusion}

This paper mainly expounds that we test some 400 tons reinforced ship lift facilities quality testing, according to national standard and model simplified calculation results, we make a scene load test for the structure platform. Through the combination of theoretical analysis and experiment, determine the platform can meet the lifting capacity design requirements, the reinforcement measures of the platform is proved to be effective and rational. They ensure the ship lift platform safety working. Through this detect and field test, solve the disuse problem cause by reaching the design working life or the structure from corrosion, to save a lot of time and money for the plant, to ensure the production progress is not affected.

Due to the active structure identification is a strong practical and empirical work, the results obtained from the theoretical analysis and post-processing is largely dependent on the field test results. In some ways, if we want to improve the accuracy and reliability of the identification results fundamentally, we should constantly perfect test means and the test procedures, and find calculation methods more accord with the actual situation, improve the accuracy of test data, to ensure the reliability of the test data.

\section{References}

1) Jiang, L.F. \& Lun, W.F. 1995. Winch type vertical ship lift platform design. Port \& Waterway engineering (12).

2) GB/T50344-2004, Technical standard for inspection of building structures. Beijing:China Building Industry Press.

3) JTJ283-1999. Code for design of steel structure in Port Engineering. Beijing: China Communications Press

4) Wang. S. X. 2007. Mechanics of Materials. Dalian: Dalian University of Technology Press 